\title{
Application of the conductive method in the engineering geology: Ruczaj district in Kraków, Poland, as a case study
}

\author{
Wojciech Klityński ${ }^{1}$ Szymon Oryński ${ }^{2} \cdot$ Chau Nguyen Dinh ${ }^{1}$
}

Received: 11 May 2019 / Accepted: 22 July 2019 / Published online: 14 August 2019

(C) The Author(s) 2019

\begin{abstract}
The Ruczaj district in Kraków is the potential building area of high flat blocks for inhabitants. This area is built of the gypsum basement covered by the soil and impermeable clay beds with several meters of thickness. The flat blocks must be set on the textured gypsum layer. In the result of the rainfall and static pressure of the blocks, the water with $\mathrm{SO}_{4}{ }^{2-}$ increases up to the groundwater level, become the great threat for the flat blocks. The water creates specific hydrogeological conditions occurring in the zone of the building's foundations. To eliminate the mentioned threat, we should determine precisely the thickness of the soil and impermeable clay as well as the depth of the gypsum basement. Based on the electromagnetic parameters of the geological formations, the Ground Conductivity Meter and DC resistivity methods were used to solve the mentioned problems.
\end{abstract}

Keywords Mineralized water $\cdot$ Ground Conductivity Meter $\cdot$ DC resistivity $\cdot$ Occam inversion $\cdot$ Near surface geophysics

\section{Introduction}

The Ruczaj district area in Kraków (Fig. 1) is a strongly developing part of the city, where many new buildings are being built. Unfortunately, there is an unexpected problem connected with the specific geological and hydrogeological conditions of this region, which compose of the soil, clay and gypsum layers. The building foundations are usually set on the textured gypsum basement; therefore, the soil and impermeable clay layers with variable thickness are to be removed. These gypsums layers are a part of the evaporative works that have been created as a result of Tortonian sea regression. The Miocene aquifer is associated with the layer of skeletal gypsum (Kleczkowski 1989; Rutkowski 1993).

This paper was presented at the CAGG 2019 Conference "Challenges in Applied Geology and Geophysics" organized at the AGH University of Science and Technology, Krakow, Poland, September 10-13, 2019.

Szymon Oryński

sorynski@igf.edu.pl

1 Faculty of Geology, Geophysics and Environmental Protection, AGH University of Science and Technology, AL. Mickiewicza 30, 30-059 Kraków, Poland

2 Institute of Geophysics, Polish Academy of Sciences, ks. Janusza 64, 01-452 Warsaw, Poland
In the case of rainfall, the infiltration water and water with $\mathrm{SO}_{4}{ }^{2-}$ from the gypsum basement flow into the zone surrounding the building foundations and became a great threat. So, the task of the engineering geologists is to determine preciously the thicknesses of the soil, clay layer and the depth of the top of the gypsum basement. There is a big resistivity contrast between those layers. Their location and approximate dimensions were determined.

\section{Conductivity and resistivity of selective soil, rocks and water}

Generally, the conductivity of soil, clay and gypsum varies in a broad interval and depends on the water content and its mineralization (Table 1). In Kraków, the conductivity of soil and clay ranges from $20-50 \mathrm{mS} / \mathrm{m}$ and $50-170 \mathrm{mS} / \mathrm{m}$, respectively, and gypsum from 1 to $10 \mathrm{mS} / \mathrm{m}$ (Pasierb 2012). The building area often amounts to a few hundred square meters, and with such small area, the soil, clay and gypsum layers can be regarded as horizontal formations. Based on the mentioned consideration and an economic cost, we decided to use the Ground Conductivity Meters (GCM) to determine the spatial distribution of the thicknesses of the soil, clay and gypsum and to check the results of GCM we used the DC resistivity and GCM soundings. There were 


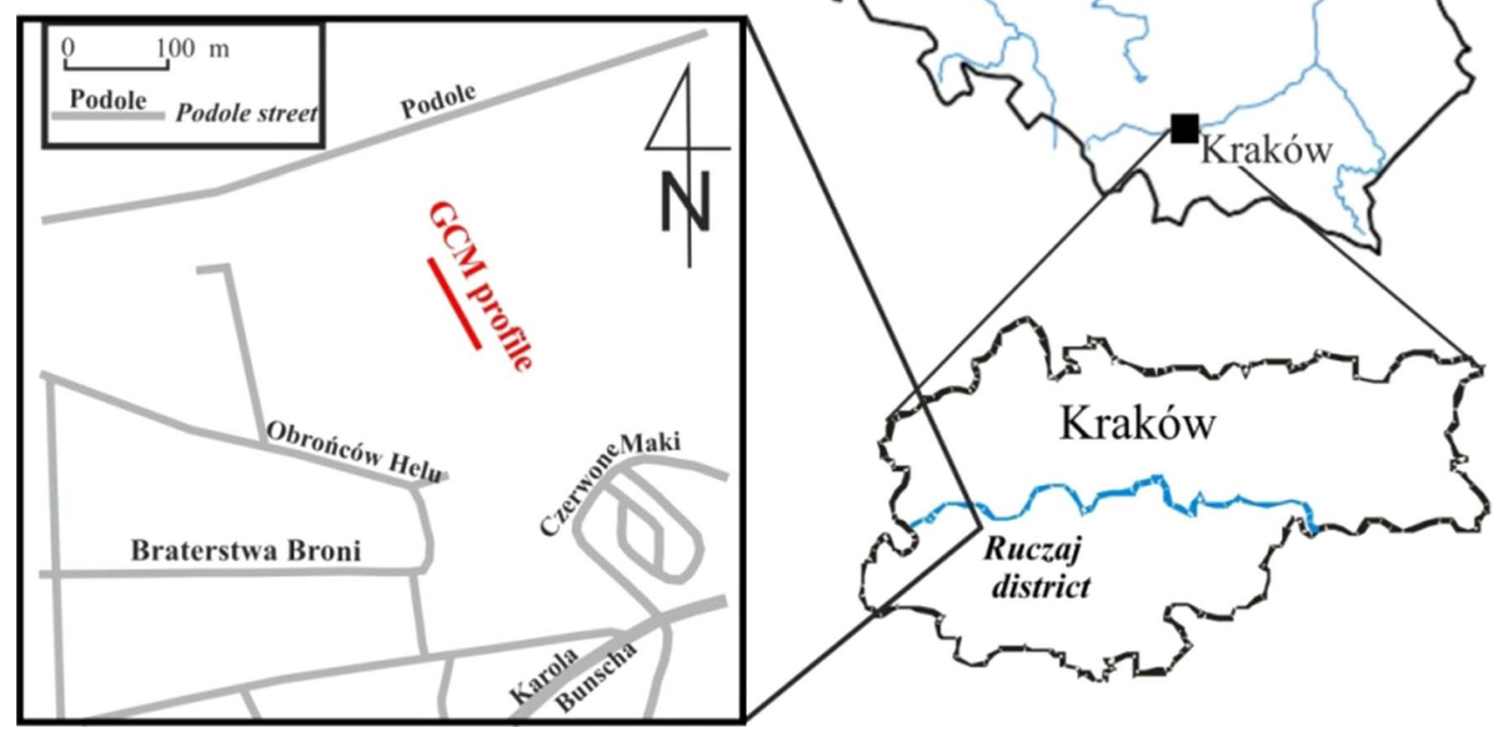

Fig. 1 Map of the survey area on the map of Kraków. See text for details

Table 1 Resistivity $(\rho)$ and conductivity $(\sigma)$ of rocks and water combined from different papers

\begin{tabular}{llll}
\hline Rock & $\rho(\Omega \mathrm{m})$ & $\sigma(\mathrm{mS} / \mathrm{m})$ & References \\
\hline Sand & $100-2500$ & $0.4-10$ & Kobranova (1989) \\
Clay & $1-100$ & $10-1000$ & \\
Loam & $5-50$ & $20-200$ & \\
Marls & $3-70$ & $14-300$ & \\
Sandstone & $500-5000$ & $2-20$ & \\
Limestone & $1-2 \times 10^{5}$ & $0.5-1 \times 10^{-2}$ & Guinea et al. (2010) \\
Gypsum with clay and/or water & $<100$ & $>10$ & \\
Solid gypsum & $>1000$ & $<1$ & Kobranova (1989) \\
Anhydrite & $10^{2}-10^{5}$ & $0.001-10$ & Keller (1966) \\
Soil & $10-800$ & $1.25-100$ & \\
Natural water & $1-100$ & $10-1000$ & \\
Brine with 3 g TDS/L & 0.15 & 6700 & \\
Brine with 20 g TDS/L & 0.05 & 20,000 & \\
\hline
\end{tabular}

no sources of high noise nearby measurement area (Neska et al. 2013).

We have considered theoretically typical applicability of those methods. We tried to detect shallowly buried, low conductive gypsum layer in a low resistive environment. The justification of the application of the DC resistivity and
GCM soundings, in this case, is very simple. There is a big resistivity contrast between layers occurring there.

The ground on which the Ruczaj settlement is mainly the Tortonian clays. In the upper part of the complex, there are thin gypsum inserts, partly eroded in the late Pleistocene and subjected to karst processes (Pociask-Karteczka 


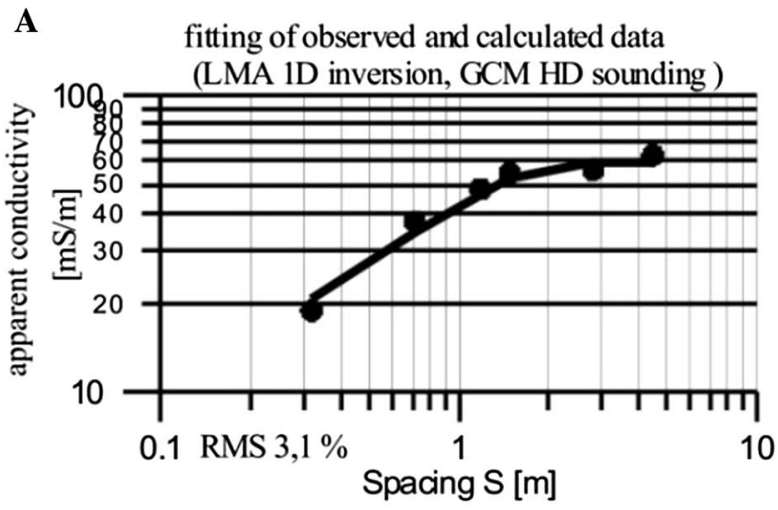

- $\bullet$ observed data

- calculated data

Models

Occam 1D

(GCM sounding)

LMA 1D

(GCM sounding)

(DC sounding)

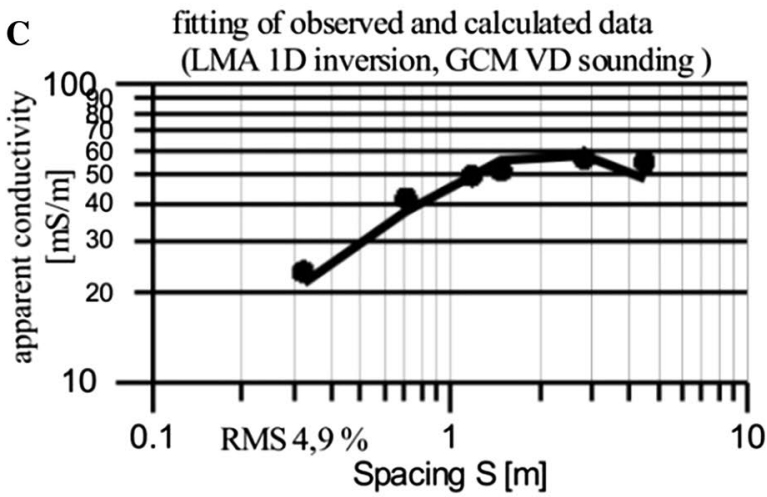

Fig. 2 Results of quantitative interpretation of GCM and DC resistivity soundings; fitting of the observed and calculated GCM data at the site $25 \mathrm{~m}$ for HD (a) and VD (c), configuration (c), results of 1D
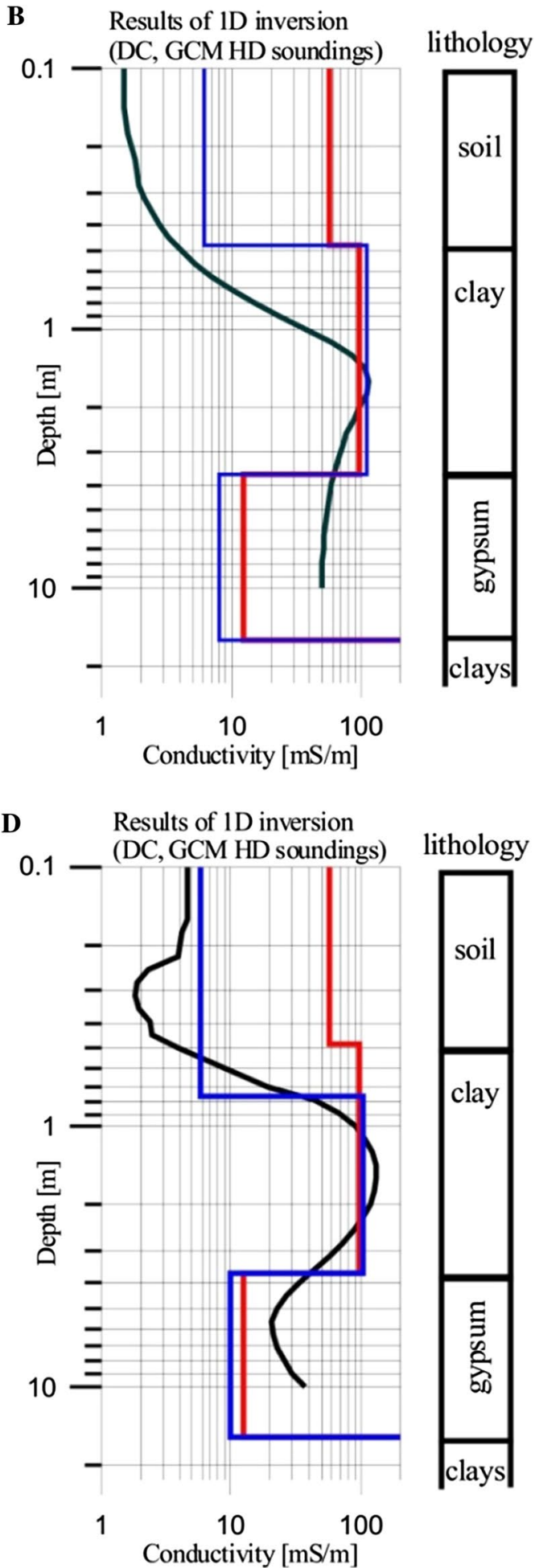

inversion of DC and GCM HD data (b), results of 1D inversion of DC and GCM VD data (d) 

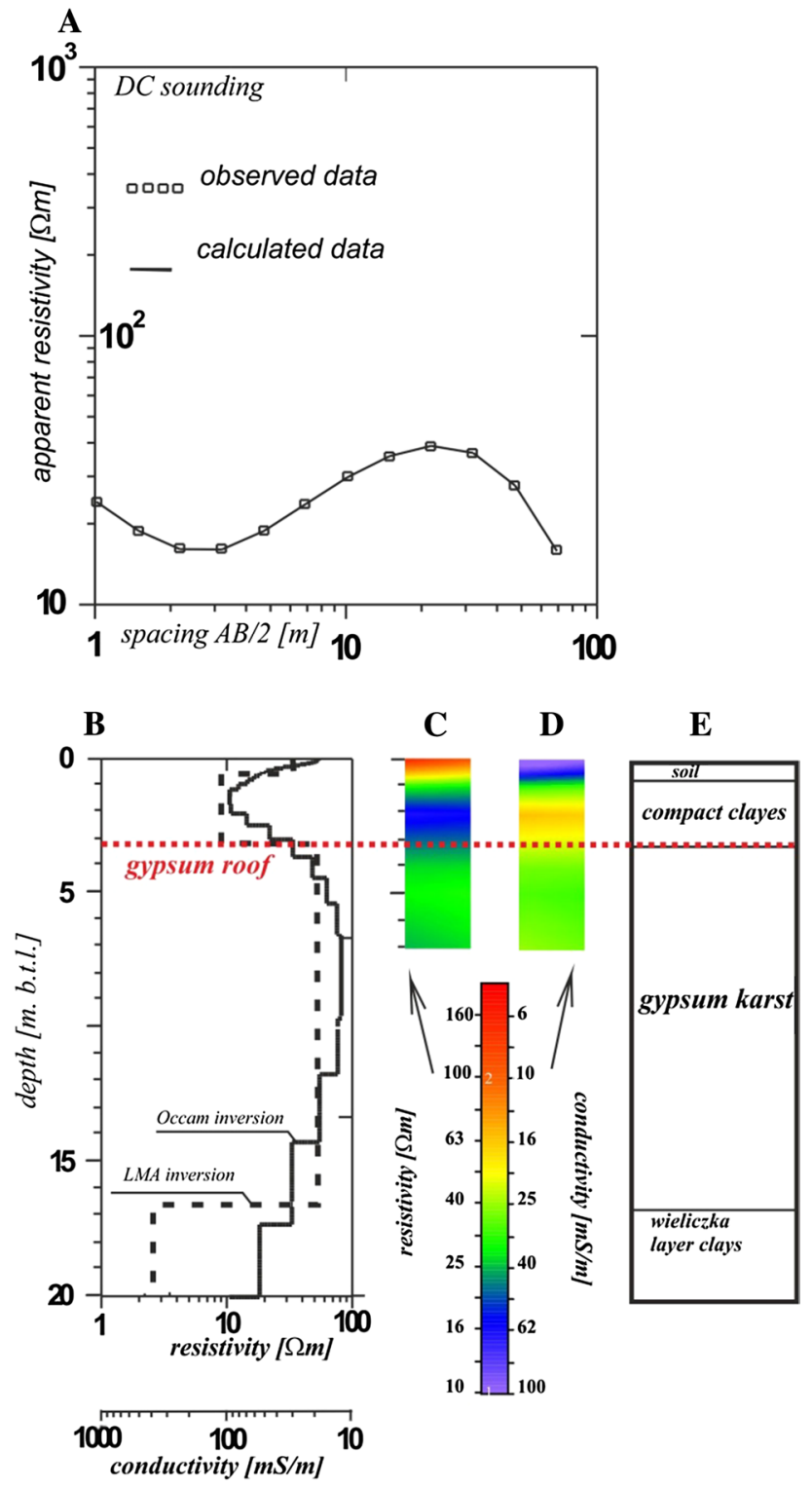

Fig. 3 Results of quantitative interpretation of DC resistivity sounding at the site $25 \mathrm{~m}$; fitting of the observed and calculated DC-R data (a), Occam and LMA models (b), colored Occam model of resistivity (c), colored Occam model of conductivity (d) and geological model (e)

1994). These gypsum layers were largely devastated during the industrialization of the area. A thin layer of Holocene alluvial deposits is lying on them, probably embedded by the nearby Wilga River (right inflow of the Vistula) and its inflows, and in some places, also the Pleistocene weathered older basement (Gradziński 1972).

Clays and loams have very low electrical resistivity or high conductivity (Table 1), but gypsum is characterized by much higher resistivity. The resistivities of rocks vary in the wide intervals. The mineral water, which saturates rocks, is characterized by relatively low resistivities and the more water in the rock, the higher rock (Antoniuk et al. 2003; Plewa and Plewa 1992).

\section{Measurements}

The conductivity method relays on a measurement of a second electromagnetic field related to the eddy current in the study medium formed by the primary electromagnetic field formed by the alternating current in the transmitting coil. The frequency of the alternating current is in a range of the audio frequency (tens $\mathrm{kHz}$ ). The measurement parameter of Ground Conductivity Meters (GCM) is the apparent conductivity $\sigma_{\mathrm{a}}(\mathrm{mS} / \mathrm{m})$ of the heterogeneous medium, which is within the footprint of a used GCM system (McNeill 1980a). The apparent conductivity at different levels of depth is measured using the horizontal (HD) and vertical (VD) magnetic dipole with a different spacing. The zone around the transmitting coil with a given frequency, where the conductivity is measured, is called as a near zone or induction zone (McNeill 1980b).

The CMD Mini-Explorer and CMD Explorer as the Ground Conductivity Meters produced by the GF Instruments, s.r.o., are designed for induction profiling. The equipment can be configured as the HD and VD system for apparent conductivity measurement, and it has six different spacing options $(s=0.32,0.71,1.18 \mathrm{~m}$ for Mini-Explorer and 1.48, 2.82, $4.49 \mathrm{~m}$ for Explorer) and operated on a frequency of $30 \mathrm{kHz}$ and $10 \mathrm{kHz}$, respectively. These configurations enable to measure the apparent conductivity of the investigated medium with different depth levels (CMD Explorer; Short guide 2016).

The GCM measurements were taken at the points with $1 \mathrm{~m}$ distance on a profile with $100 \mathrm{~m}$ long in the district Ruczaj of Kraków (Poland). To recognize the geological medium, benchmark DC resistivity soundings, with a measuring step of $25 \mathrm{~m}$ along the same profile, were carried out.

To verify GCM interpretation results, the DC measurements were taken using the Schlumberger four-electrode system (Klityński et al. 2014). The data obtained from both DC resistivity measurements and GCM soundings were quantitatively interpreted using two different algorithms Occam and Levenberg-Marquardt (LMA); then, the results were combined for the determination of the studied medium. The result of the LMA interpretation is a model with layers separated by the sharp boundaries, while the result of the Occam interpretation is a model with a curve presenting the resistivity, which fluently changes from layer to the other (Constable et al. 1987).

The LMA algorithm involves the iterative adjustment of the model curve to the empirical data (measurement curves) and the parameters of the geoelectrical cross section calculated on their basis. One-dimensional inversion by this 


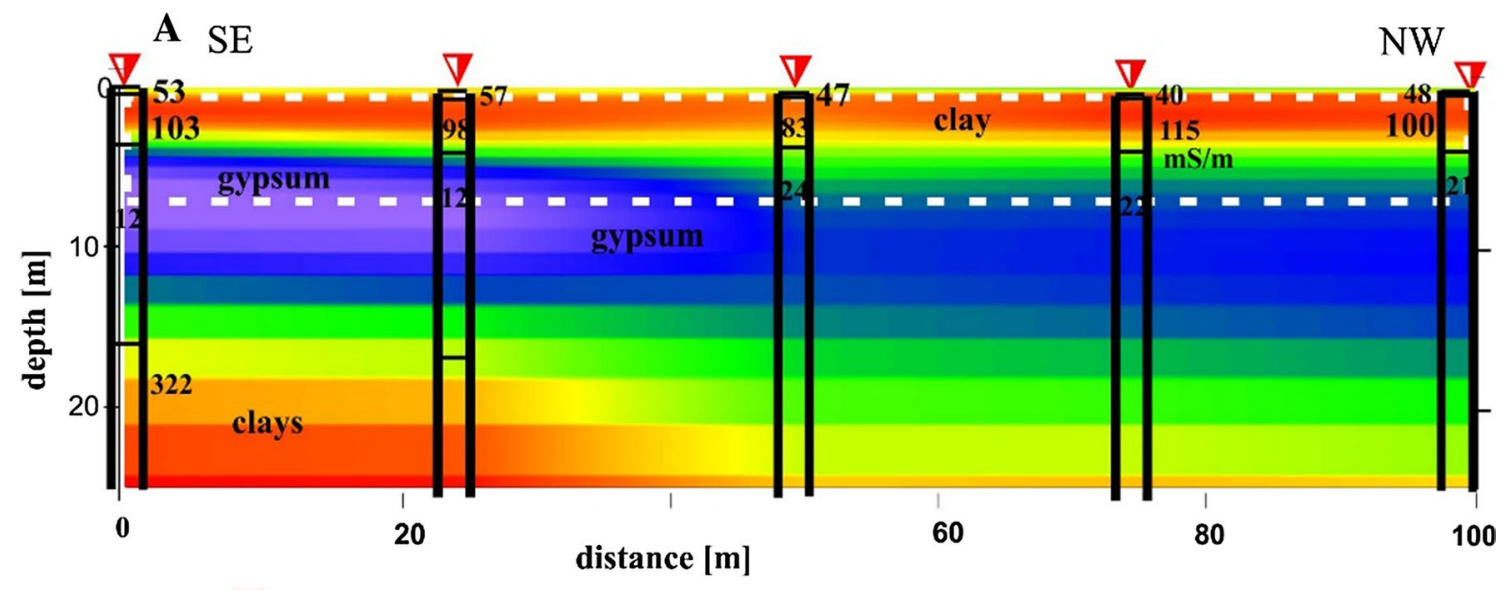

$\nabla$ DC Schlumberger sounding 436 counductivity $[\mathrm{mS} / \mathrm{m}]$

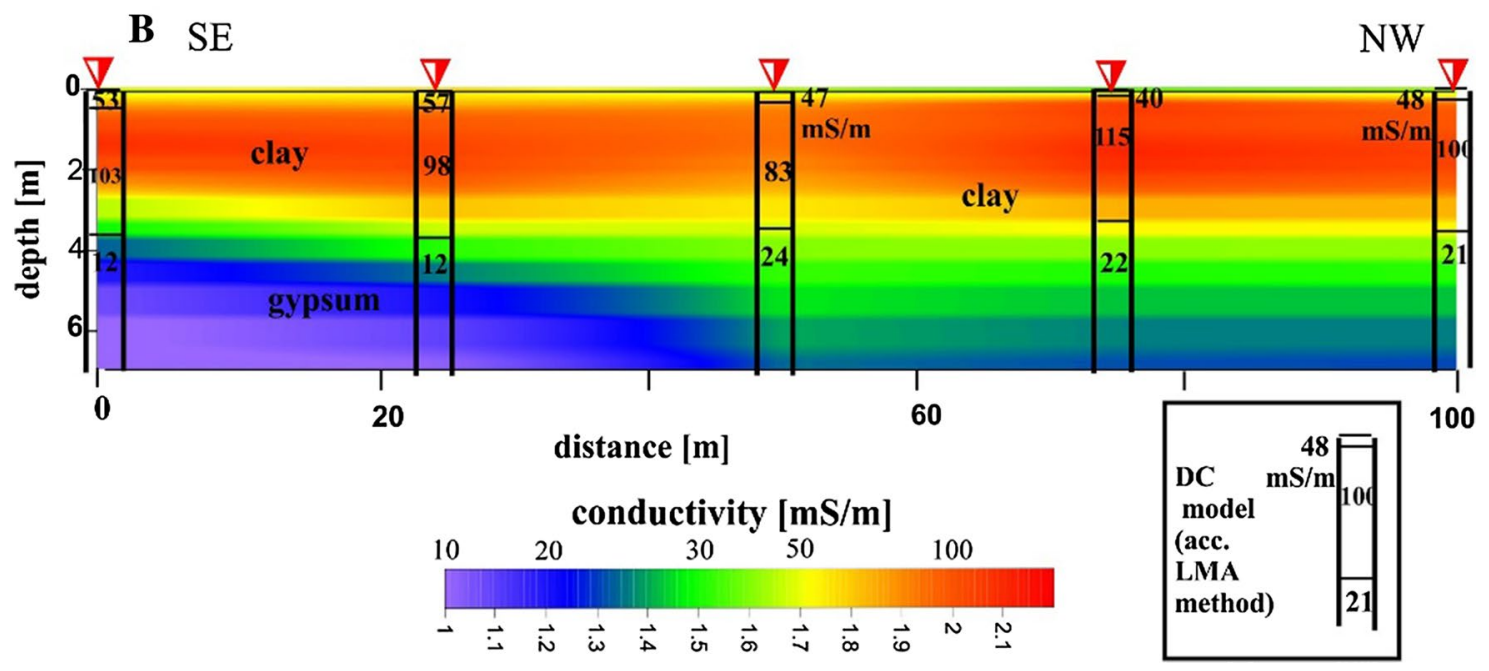

Fig. 4 Conductivity cross sections using 1D Occam inversion of DC sounding data and results of 1D LMA inversion of DC soundings

method is based on optimization of the error function, i.e., deviations between field (empirical) curves and those calculated from the model using the Levenberg-Marquardt algorithm (Levenberg 1944).

Inverting 1D according to the Occam's algorithm is a method of calculating one-dimensional resistivity distribution in a geological center (Oryński et al. 2019). The basic assumptions of this method are striving to achieve the most smooth and the most simple model (Jóźwiak 2013). It is an iterative algorithm in which the starting model is a homogeneous half-space, and during the iteration process, the resistivities of individual layers are modified (Nowozynski and Slezak 2013). The error minimization procedure was constructed in such a way that the resistivity contrasts were as small as possible (Reynolds 2011).

\section{Results and discussion}

The measured apparent conductivities as a function of the GCM system arrays are presented in Fig. 2a, c, and they are compared with results of DC resistivity method as shown in Fig. 2b, d. The interpretation of this curve indicates three layers: The first is the soil with the conductivity $\sim 6 \mathrm{mS} / \mathrm{m}$ with a thickness of several dozen centimeters. Beneath them, there is the clay layer with conductivity close to $100 \mathrm{mS} / \mathrm{m}$ and thickness about $3 \mathrm{~m}$.

Under the clay layer, there is the gypsum complex with conductivity about $8 \mathrm{mS} / \mathrm{m}$ with thickness increasing from 12 to over $20 \mathrm{~m}$ in SE-NW direction (Fig. 2b, d). The deeper layer is not observed by the GCM method, due to its limited footprint. It is characterized by high conductivity (about $300 \mathrm{mS} / \mathrm{m}$ ), which is recognized by the DC resistivity sounding method. This layer belongs to Miocene clay formation (Kleczkowski 1989). A very similar situation, as described above, is visible for the DC resistivity sounding results, 

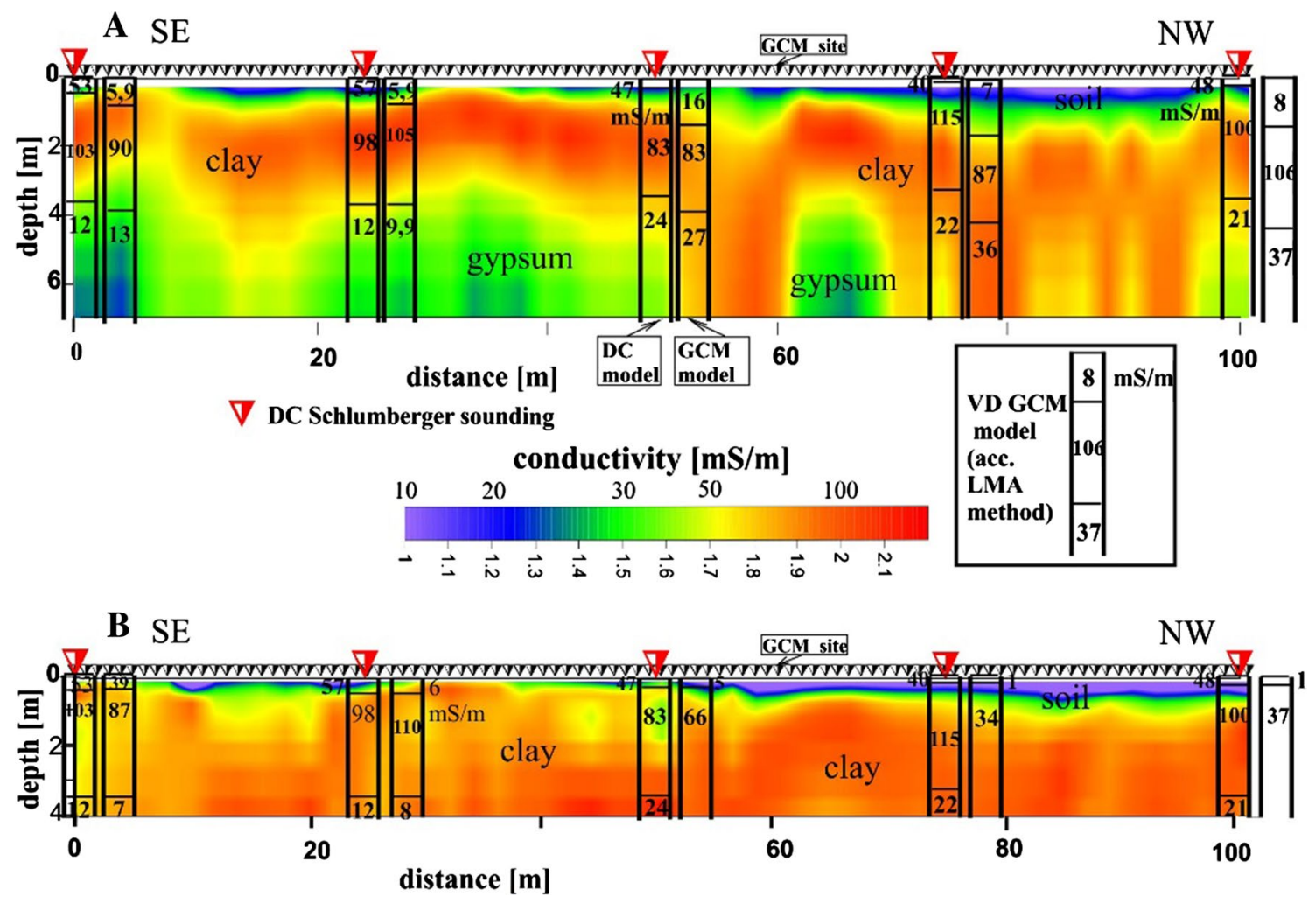

Fig. 5 Conductivity cross sections using 1D Occam inversion of GCM data for HD (a) and VD (b) configurations and collating results of 1D LMA inversion of DC soundings and GCM data for the corresponding point located along with the profile

presented in Fig. 3. However, in this case, the depth range is almost twice as large and up to $20 \mathrm{~m}$. A high conductive layer, interpreted as compact alluvial clay, is strongly visible, and also there is a strong boundary between it and high resistive gypsum layer. The Miocene basement (named Wieliczka formation clays as shown in Fig. 3e) is much better visible for deeper DC sounding than in the previous case.

Interpretation of the data obtained by both DC and GCM soundings are performed using the LMA, Occam algorithms and the Interpex IX1D software. Parallel with the mentioned software, the authors also used the linear filtering method to make the curve presenting the GCM sounding data corresponding to the assumed geoelectrical model (Ghosh 1971; Das and Verma 1981; Koefoed et al. 1972), while the GCM curve for the horizontal arrangement model was calculated using the Abramova's filter (Loke 2003). For the precise interpretation of the GCM sounding, the iterative method was used, which is upon on founding the minimum of the error function (RMS). The used interaction algorithms were taken from DLIB library (King 2009).

Results of quantitative interpretation are presented as a conductivity cross sections of 1D Occam inversion of DC sounding data (Fig. 4) and 1D Occam inversion of GCM data (Fig. 5) The results of the LMA algorithm are presented as a well in the place of soundings, while the results of Occam inversion are interpolated between soundings. Moreover, results of DC-R inversion are presented in two variants: up to $20 \mathrm{~m}$ of depth (Fig. 4a) and up to $6 \mathrm{~m}$ of depth (Fig. 4b). The first one corresponds to the maximum range, the second to be better compared with the GCM.

The horizontal resolution of the interpreted DC data (Fig. 4a, b) is worse than that of the GCM soundings (Fig. 5a, b), since the distance between two points of the sounding measurements for DC amounted to $25 \mathrm{~m}$, while for GCM, only $3 \mathrm{~m}$.

The following figure shows the conductivity cross sections of 1D Occam inversion of GCM data for HD (Fig. 5a) and VD (Fig. 5b) configurations. They are compared with the results of 1D LMA DC resistivity results. The color scale used in these two figures is the same.

\section{Conclusions}

Due to the conductivity of the soil, impermeable clay and gypsum layers vary from a few to above $100 \mathrm{mS} / \mathrm{m}$ and there is a significant resistivity contrast; the conductive method (GCM) was successfully used at the Ruczaj district in Krakow. The determined conductivity and thickness are equal to near $6 \mathrm{mS} / \mathrm{m}, 40 \mathrm{~cm}$, near $100 \mathrm{mS} / \mathrm{m}, 3 \mathrm{~m}$ for soil and clay 
layers, respectively. The thicknesses of the mentioned layers increase in a S-N direction. These results were similar to that measured by the DC sounding, but the vertical and horizontal resolutions of GCM data are better than that of the DC method. The effect is closely related to the greater sensitivity and shorter distance between the measurement points of the GCM method. Our results correspond very well with those received earlier, near to the studied area, using the VLF-EM and GCM method (Foltyn et al. 2015; Oryński et al. 2016; Orynski and Klitynski 2018).

The layers occurring at the level deeper around $7 \mathrm{~m}$ are invisible by the GCM method due to its limited footprint, but the deep layer was determined by the DC sounding method. It is worth adding such deep layer which need not be determined for the building engineering.

Though the footprint of the HD arrangement in GCM method is shallower than that of the VD arrangement, the fit curve for the data obtained by the GCM is better than those of the data gained from the DC method.

From the economic and the resolution point of view, the GCM method can be regarded as an alternative method related to the DC method, especially for the shallow zone (Tomecka-Suchoń et al. 2017).

In addition, it is worth noting that, regarding the fact that in GCM method, the device does not apply directly to the ground, there are some difficulties with the correct designation of the first layer conductivity. Therefore, it is much lower for GCM than for DC resistivity results (Kowalczyk et al. 2017).

It is worth adding the authors who not only qualitatively interpreted but also quantitatively determined the conductivity and thickness of the geological beds upon on the GCM data. The quantitative interpretation relays on creating the cross-sectional model correspondent to the measured data.

Acknowledgements This paper was financially supported by the research subsidy nr. 16.16.140.315 at the Faculty of Geology Geophysics and Environmental Protection of the AGH University of Science and Technology, Krakow, Poland, 2019.

Open Access This article is distributed under the terms of the Creative Commons Attribution 4.0 International License (http://creativeco mmons.org/licenses/by/4.0/), which permits unrestricted use, distribution, and reproduction in any medium, provided you give appropriate credit to the original author(s) and the source, provide a link to the Creative Commons license, and indicate if changes were made.

\section{References}

Antoniuk J, Mościcki WJ, Janicki K (2003) Geoelectric investigation of migration of chemically-polluted waters from the post-flotation settlement reservoir "Żelazny Most”. IGSMiE PAN, Kraków, pp 383-391

Constable SC, Parker RL, Constable CG (1987) Occam's inversion: a practical algorithm for generating smooth models from electromagnetic sounding data. Geophysics 52(03):289-300

Das UC, Verma SK (1981) Versatility of digital linear filters used in computing resistivity and EM sounding curves. Geoexploration 18:297-310

Foltyn N, Oryński S, Klityński W (2015) Flooded zones recognition with the use of ground conductivity metres. In: Conference paper: 77th EAGE conference and exhibition 2015. https://doi. org/10.3997/2214-4609.201412538

Ghosh DP (1971) The application of linear filter theory to the direct interpretation of geoelectrical sounding measurements. Geophys Prospect 19:192-217

Gradziński R (1972) Przewodnik geologiczny po okolicach Krakowa. Wyd. Geol., Warszawa (in Polish)

Guinea A, Playa E, Rivero L, Himi M, Bosch R (2010) Geoelectrical classification of gypsum rocks. Surv Geophys 31:557-580

Jóźwiak W (2013) Electromagnetic study of lithospheric structure in the marginal zone of East European Craton in NW Poland. Acta Geophys 61(5):1101-1129. https://doi.org/10.2478/s1160 $0-013-0127-z$

Keller GV (1966) Electrical properties of rocks and minerals. In: Clark SP (ed) Handbook of physical constants, Memoir 97. The Geological Society of America, New York

King DE (2009) Dlib-ml: a machine learning toolkit. J Mach Learn Res 10:1755-1758. https://doi.org/10.1145/1577069.1755843

Kleczkowski AS (1989) Szkic zagadnień hydrogeologicznych Krakowa. Prz Geol 37(6):323-326 (in Polish)

Klityński W, Stelmach K, Stefaniuk S, Karczewski J (2014) Recognition of building sandstone deposit with the use of geophysical resistivity sounding and georadar methods. Prz Geol 62(10/2):621-628 (in Polish)

Kobranova VN (1989) Petrophysics. Springer, Berlin

Koefoed O, Ghosh DP, Polman GJ (1972) Computations of type curves for electromagnetic depth sounding with a horizontal transmitting coil by means of a digital linear filter. Geophys Prospect 20:406-420

Kowalczyk S, Żukowska KA, Mendecki MJ, Łukasiak D (2017) Application of electrical resistivity imaging (ERI) for the assessment of peat properties: a case study of the Całowanie Fen, Central Poland. Acta Geophys 65(1):223-235. https://doi. org/10.1007/s11600-017-0018-9

Levenberg K (1944) A method for the solution of certain non-linear problems in least squares. Q Appl Math 2:164-168

Loke H (2003) Rapid 2D resistivity \& IP inversion using the leastsquares method. Geotomo Software

McNeill JD (1980a) Electrical conductivity of soils and rocks. Technical note TN-5. Geonics Limited, Mississauga

McNeill JD (1980b) Electromagnetic terrain conductivity measurement at low induction numbers. Technical note TN-6. Geonics Limited, Mississauga

Neska A, Neska M, Reda J (2013) On the influence of DC railway noise on variation data from Belsk and Lviv geomagnetic observatories. Acta Geophys 61(2):385-403. https://doi.org/10.2478/ s11600-012-0058-0

Nowożyński K, Ślęzak K (2013) Analysis and usage of linear relationships between the magnetic field components recorded by INTERMAGNET. Acta Geophys 61(3):511-534. https://doi.org/10.2478/ s11600-013-0103-7

Oryński S, Klityński W (2018) Combined quantitative interpretation of GCM and DC sounding data from selected area in Cracow, Poland. In: Conference paper: the 24th EM Induction Workshop, Helsingør, Denmark, 13-20 Aug 2018 
Oryński S, Okoń M, Klityński W (2016) Very low frequency electromagnetic induction surveys in hydrogeological investigations; case study from Poland. Acta Geophys 64(6):2322. https://doi. org/10.1515/acgeo-2016-0092

Oryński S, Klityński W, Neska A, Ślęzak K (2019) Deep lithospheric structure beneath the Polish part of the East European Craton as a result of magnetotelluric surveys. Stud Geophys Geod 63(2):273289. https://doi.org/10.1007/s11200-017-1264-7

Pasierb B (2012) Resistivity topography in prospecting geological surface and anthropogenic objects. Tech Trans 23(109):201-209

Plewa M, Plewa S (1992) Petrofizyka. Wyd. Geol., Kraków (in Polish)

Pociask-Karteczka J (1994) Przemiany stosunków wodnych na obszarze Krakowa. Zesz. Nauk UJ, 1914, Pr Geogr 96 (in Polish)
Reynolds JM (2011) An introduction to applied and environmental geophysics (2). Wiley, Chichester

Rutkowski J (1993) Objaśnienia do Szczegółowej Mapy Geologicznej Polski w skali 1: 50 000, ark. Kraków (973). Państw Inst Geol, Warszawa (in Polish)

Short guide for electromagnetic conductivity mapping and tomography GF Instruments (2016) Ver. 1.3. GF Instruments, Brno, Czech Republic

Tomecka-Suchoń S, Żogała B, Gołębiowska T, Dzik G, Dzik T, Jochymczyk K (2017) Application of electrical and electromagnetic methods to study sedimentary covers in high mountain areas. Acta Geophys 65(4):743-755. https://doi.org/10.1007/s1160 0-017-0068-Z 